\title{
AN ANALYTICAL TECHNIQUE TO OBTAIN HIGHER-ORDER APPROXIMATE PERIODS FOR THE NONLINEAR OSCILLATOR
}

\author{
Md Sazzad Hossien Chowdhury ${ }^{1 *}$, Md. Alal Hosen ${ }^{2}$, Mohammad \\ YEAKUB ALI ${ }^{3}$ AND AHMAD FARIS ISMAIL ${ }^{4}$ \\ ${ }^{1}$ Department of Science in Engineering, Kulliyyah of Engineering, \\ International Islamic University Malaysia, PO Box 10, 50728 Kuala Lumpur, Malaysia. \\ ${ }^{2}$ Department of Mathematics, Rajshahi University of Engineering and Technology, \\ Rajshahi-6204, Bangladesh \\ ${ }^{3}$ Department of Manufacturing and Material Engineering, \\ ${ }^{4}$ Department of Mechanical Engineering, \\ Kulliyyah of Engineering, International Islamic University Malaysia, \\ PO Box 10, 50728 Kuala Lumpur, Malaysia. \\ *Corresponding author: sazzadbd@iium.edu.my \\ (Received: $4^{\text {th }}$ June 2018; Accepted: $21^{\text {st }}$ Sept2018; Published on-line: $1^{\text {st }}$ Dec 2018) \\ https://doi.org/10.31436/iiumej.v19.i2.943
}

\begin{abstract}
In this paper, an analytical technique has been proposed to obtain higherorder approximate periods for the nonlinear oscillator with the square of the angular frequency depending quadratically on the velocity which is based on the harmonic balance method (HBM). Analytical investigation of the appeared set of nonlinear algebraic equations is usually cumbersome, which is addressed by the proposed technique in a novel way. In this paper, this limitation is eradicated and provides desired results without much numerical complexity. Additionally, a new suitable truncation formula has been introduced in which the approximate periods measure much better results than existing periods. The proposed technique is applied to the benchmark nonlinear oscillatory problem where the square of the angular frequency depends quadratically on the velocity to illustrate its novelty, reliability, and wider applicability. It is remarkably improtant to note that, using the proposed technique, a third-order approximate period gives an excellent agreement as compared with the exact ones.
\end{abstract}

ABSTRAK: Kertas cadangan ini membincangkan tentang teknik analitikal bagi menghasilkan tempoh anggaran lebih tinggi pada sistem bukan linear dengan kuasa dua frekunsi angular halaju kuadratik, iaitu bergantung pada kaedah imbangan harmoni (HBM). Penyelidikan analitikal pada set persamaan algebra bukan linear selalunya adalah rumit, iaitu dibincangkan secara teknik cadangan baru. Kertas ini, menghapuskan kekurangan ini dan menghasilkan keputusan tanpa banyak kerumitan numerik. Selain itu, formula baru yang ringkas dan sesuai ini diperkenalkan dengan tempoh anggaran ukuran keputusan lebih bagus daripada tempoh sedia ada. Teknik yang dicadangkan ini digunakan sebagai penanda aras pada masalah osilator bukan linear dengan frekunsi angular halaju kuadratik bagi memperlihatkan kebaharuan, kebergantungan dan keluasan pada kegunaannya. Pengunaan kaedah ini adalah sangat luar biasa.

KEYWORDS: approximate periods; truncation principle; harmonic balance method; nonlinear oscillator; analytical technique 


\section{INTRODUCTION}

Nonlinear oscillations have important aspects for areas including physical sciences, mechanical structures, engineering and other disciplines [1,2] which appear mathematically in the form of nonlinear differential equations (NDEs). The solution procedure of obtaining approximate solutions of linear differential equations is comparatively easy and well established. In contrast, the solution procedure of obtaining approximate solutions of NDEs remains less available to this day. It is often more difficult to get an analytic approximation than a numerical one. A few nonlinear systems can be solved explicitly, and the numerical methods especially the most well-known Runge-Kutta fourth order method are frequently used to calculated approximate solutions. However, in stiff differential equations and chaotic differential equations, the numerical schemes do not always give accurate results, thus presenting a big challenge to numerical analysis. In this situation, many researchers have shown an intensifying interest in the field of analytical approximate techniques. The most widely used analytical technique for solving nonlinear equations associated with oscillatory systems is the perturbation method [3-6], which is the most versatile tool available in nonlinear analysis of engineering problems, and it is constantly being developed and applied to ever more complex problems. However, the standard perturbation methods have many limitations, and they do not yield for strongly nonlinear oscillators.

As a result, to overcome this shortcoming, in recent years, a large variety of modified perturbation techniques are commonly used in nonlinear systems, especially for strongly nonlinear oscillators. There modified methods include optimal homotopy asymptotic method [7], homotopy perturbation method [8-10], modified homotopy perturbation method [11], modified He's homotopy perturbation method [12-14], modified Lindsted-Poincare method [15], He's modified Lindsted-Poincare method [16], and modified multiple time scale method [17].

In the recent past, some other approximation techniques have been investigated. These techniques include the He's max-min approach [18], elliptic balance [19], algebraic [20], the differential transform approach [21], He's frequency-amplitude formulation [22], iteration [23], the variational approach [24], energy balance [25-29] methods, and the rational harmonic balance method [30]. All have been paid much attention in order to determine periodic solutions of strongly nonlinear oscillatory problems. In fact, to the best of our knowledge, in the energy balance method and some other methods, there is no clear idea to obtain higher-order approximate solutions. Moreover, only first-order approximation has been considered, which does not provides sufficient accuracy.

In this situation, an analytical technique has been proposed based on the harmonic balance method [31-38] to obtain approximate periods to the nonlinear oscillator with the square of the angular frequency depending quadratically on the velocity. The higher-order approximate period (mainly third-order approximation) has been obtained. The proposed technique not only provides accurate results but is also more convenient and efficient for solving more complex nonlinear oscillatory problems. Moreover, using a suitable truncation formula gives approximate periods that are very near to the next higher-order approximation and avoids a lot of calculation. This is the main advantage of the proposed technique presented in this article.

The rest of this paper is organized as follows: In section 2, we give the outline of the solution approaches of the harmonic balance method. In section 3, we implement the harmonic balance method to the nonlinear oscillator with the square of the angular frequency depending quadratically on the velocity. The results and a detailed discussion have been explained extensively in section 4. Concluding remarks are given in section 5. 


\section{SOLUTION APPROACHES}

Consider a general second-order nonlinear differential equation and initial conditions as follows:

$$
\ddot{x}+\omega_{0}^{2} x=-\varepsilon f(x, \dot{x}), \quad\left[x(0)=a_{0}, \dot{x}(0)=0\right]
$$

where $f(x, \dot{x})$ is a nonlinear function such that $f(-x,-\dot{x})=-f(x, \dot{x}), \omega_{0} \geq 0$ and $\varepsilon$ is a constant.

A periodic solution of Eq. (1) can be assumed as

$$
x=a_{0}(\rho \cos (\omega t)+u \cos (3 \omega t)+v \cos (5 \omega t)+w \cos (7 \omega t)+z \cos (9 \omega t) \cdots)
$$

where $a_{0}, \rho$ and $\omega$ are constants. If $\rho=1-u-v-\cdots$, then the solution to Eq. (2) easily satisfies the initial conditions given in Eq. (1). Substituting Eq. (2) into Eq. (1) and expanding $f(x, \dot{x})$ in a Fourier series, reduces it to an algebraic identity

$$
\begin{gathered}
a_{0}\left[\rho\left(\omega_{0}^{2}-\omega^{2}\right) \cos (\omega t)+u\left(\omega_{0}^{2}-9 \omega^{2}\right) \cos (3 \omega t)+\cdots\right. \\
+F_{3}\left(a_{0}, u, \cdots\right.
\end{gathered}
$$

By comparing the coefficients of equal harmonic terms of Eq. (3), the following nonlinear algebraic equations are obtained.

$$
\rho\left(\omega_{0}^{2}-\omega^{2}\right)=-\varepsilon F_{1}, \quad u\left(\omega_{0}^{2}-9 \omega^{2}\right)=-\varepsilon F_{3}, \quad v\left(\omega_{0}^{2}-25 \omega^{2}\right)=-\varepsilon F_{5}, \cdots
$$

Using the first equation, $\omega^{2}$ is eliminated from all the remaining equations of Eq. (4). Thus, Eq. (4) takes the following form

$$
\rho \omega^{2}=\rho \omega_{0}^{2}+\varepsilon F_{1}, \quad 8 \omega_{0}^{2} u \rho=\varepsilon\left(\rho F_{3}-9 u F_{1}\right), \quad 24 \omega_{0}^{2} v \rho=\varepsilon\left(\rho F_{5}-25 v F_{1}\right), \ldots
$$

Substituting $\rho=1-u-v-\cdots$, and then simplifying, second-, third- equations of Eq. (5) takes the following form.

$$
u=G_{1}\left(\omega_{0}, \varepsilon, a_{0}, u, v, \cdots, \lambda_{0}\right), \quad v=G_{2}\left(\omega_{0}, \varepsilon, a_{0}, u, v, \cdots, \lambda_{0}\right), \cdots
$$

where $G_{1}, G_{2}, \cdots$ exclude, respectively, the linear terms of $u, v, \cdots$.

Whatever the values of $\omega_{0}, \varepsilon$ and $a_{0}$, there exists a parameter $\lambda_{0}\left(\omega_{0}, \varepsilon, a_{0}\right)<<1$, such that $u, v, \cdots$ are expandable in the following power series in terms of $\lambda_{0}$ as

$$
u=U_{1} \lambda_{0}+U_{2} \lambda_{0}^{2}+\cdots, \quad v=V_{1} \lambda_{0}+V_{2} \lambda_{0}^{2}+\cdots, \quad \cdots
$$

where $U_{1}, U_{2}, \cdots, V_{1}, V_{2}, \cdots$ are constants.

Finally, substituting the values of $u, v, \cdots$ from Eq. (7) into the first equation of Eq. (5), the approximate angular $\omega$ is determined. This completes the determination for the approximate periods obtained by the relation $T=\frac{2 \pi}{\omega}$. 


\section{NUMERICAL EXAMPLE}

Consider a nonlinear oscillator which was studied in [6,15,31-32] as:

$$
\ddot{x}+\left(1+\dot{x}^{2}\right) x=0
$$

In Eq. (2), a second-order approximate solution of Eq. (8) is

$$
x=a_{0}(\rho \cos (\omega t)+u \cos (3 \omega t))
$$

Substituting Eq. (9) along with $\rho=1-u$ into Eq. (8), then simplifying and equating the coefficients of $\cos (\omega t)$ and $\cos (3 \omega t)$ to zero, the following residuals are obtained.

$$
\begin{aligned}
& 1-\omega^{2}+a_{0}^{2} \omega^{2} / 4-u+\omega^{2} u+a_{0}^{2} \omega^{2} u / 2+11 a_{0}^{2} \omega^{2} u^{2} / 4-7 a_{0}^{2} \omega^{2} u^{3} / 2=0, \\
& -a_{0}^{2} \omega^{2} / 4+u-9 \omega^{2} u+5 a_{0}^{2} \omega^{2} u / 4-7 a_{0}^{2} \omega^{2} u^{2} / 4+3 a_{0}^{2} \omega^{2} u^{3}=0 .
\end{aligned}
$$

From the first equation of Eq. (10), it becomes

$$
\omega^{2}=(1-u) /\left(1-a_{0}^{2} / 4-u-a_{0}^{2} u / 2-11 a_{0}^{2} u^{2} / 4+7 a_{0}^{2} u^{3} / 2\right) .
$$

Substituting Eq. (11) into the second equation of Eq. (10), the nonlinear algebraic equation of $u$ is obtained as:

$$
u=\lambda_{0}\left(-1+5 u-14 u^{2}+32 u^{2} / a_{0}^{2}+8 u^{3}+2 u^{4}\right), \quad \lambda_{0}=a_{0}^{2} / 32 .
$$

Therefore, the power series solution of Eq. (12) in terms of $\lambda_{0}$ is

$$
u=-\lambda_{0}-5 \lambda_{0}^{2}+\left(-39+32 / a_{0}^{2}\right) \lambda_{0}^{3}+\cdots
$$

Substituting the value of $u$ from Eq. (13) into Eq. (11) and then simplifying the secondorder approximate angular frequency results in:

$$
\omega=\left(1+\frac{a_{0}^{2}}{8}+\frac{3 a_{0}^{4}}{256}+\frac{3 a_{0}^{6}}{4096}+\frac{a_{0}^{8}}{8192}+\cdots\right),
$$

and using the relation $T=\frac{2 \pi}{\omega}$, the second-order approximate period of Eq. (8) is:

$$
T_{2}=2 \pi\left(1-\frac{a_{0}^{2}}{8}+\frac{a_{0}^{4}}{256}+\frac{a_{0}^{6}}{4096}-\frac{7 a_{0}^{8}}{65536}+\cdots\right)
$$

Considerable calculation is saved and improved results are obtained if we use the truncation principle in Eq. (10). The higher-order terms of $u$ greater than second-order have no effect on the value of the unknowns $u$ and $\omega$. So, we may ignore greater than secondorder terms of $u$; but half of the second-order terms are considered. This is called the truncation principle. After using the truncation principle, Eq. (10) can be transformed into

$$
\begin{aligned}
& 1-\omega^{2}+a_{0}^{2} \omega^{2} / 4-u+\omega^{2} u+a_{0}^{2} \omega^{2} u / 2+11 a_{0}^{2} \omega^{2} u^{2} / 8=0, \\
& -a_{0}^{2} \omega^{2} / 4+u-9 \omega^{2} u+5 a_{0}^{2} \omega^{2} u / 4-7 a_{0}^{2} \omega^{2} u^{2} / 8=0 .
\end{aligned}
$$


From the first equation of Eq. (16), it can be easily written as

$$
\omega^{2}=(1-u) /\left(1-a_{0}^{2} / 4-u-a_{0}^{2} u / 2-11 a_{0}^{2} u^{2} / 8\right) .
$$

Substituting $\omega^{2}$ into the second equation of Eq. (16), the nonlinear algebraic equation of $u$ is reduce to:

$$
u=\lambda_{0}\left(-1+5 u-21 u^{2} / 2+32 u^{2} / a_{0}^{2}-2 u^{3}\right)
$$

where $\lambda_{0}$ is given in Eq. (12).

The power series solution of Eq. (18) in terms of $\lambda_{0}$ is:

$$
u=-\lambda_{0}-5 \lambda_{0}^{2}+\left(-71 / 2+32 / a_{0}^{2}\right) \lambda_{0}^{3}+\cdots
$$

Substituting the value of $u$ from Eq. (19) into Eq. (17) the second-order approximate angular frequency becomes:

$$
\omega=\left(1+\frac{a_{0}^{2}}{8}+\frac{3 a_{0}^{4}}{256}+\frac{a_{0}^{6}}{16384}-\frac{35 a_{0}^{8}}{131072}-\frac{2065 a_{0}^{10}}{16777216}+\cdots\right)
$$

and the approximate period of oscillation in using the truncation principle is:

$$
T_{2}^{\text {truc }}=2 \pi\left(1-\frac{a_{0}^{2}}{8}+\frac{a_{0}^{4}}{256}+\frac{5.6 a_{0}^{6}}{6144}+\frac{15 a_{0}^{8}}{131072}+\cdots\right)
$$

By the same mathematical manipulation as stated above, the higher-order approximations have been obtained using the proposed technique. In this paper, a third-order approximation is

$$
\begin{gathered}
x(t)=a_{0} \cos (\omega t)+a_{0} u(\cos (3 \omega t)-\cos (\omega t))+a_{0} v(\cos (5 \omega t) \\
-\cos (\omega t))
\end{gathered}
$$

Substituting Eq. (22) into Eq. (8), then simplifying and equating the coefficients of $\cos (\omega t)$ , $\cos (3 \omega t)$ and $\cos (5 \omega t)$ equal to zero, the related equations are

$$
\begin{aligned}
& 1-\omega^{2}+a_{0}^{2} \omega^{2} / 4-u+\omega^{2} u+a_{0}^{2} \omega^{2} u / 2+11 a_{0}^{2} \omega^{2} u^{2} / 4-7 a_{0}^{2} \omega^{2} u^{3} / 2 \\
& -v+\omega^{2} v+\cdots=0, \\
& -a_{0}^{2} \omega^{2} / 4+u-9 \omega^{2} u+5 a_{0}^{2} \omega^{2} u / 4-7 a_{0}^{2} \omega^{2} u^{2} / 4+3 a_{0}^{2} \omega^{2} u^{3}+3 a_{0}^{2} \omega^{2} v \\
& -a_{0}^{2} \omega^{2} u v / 2+\cdots=0, \\
& -7 a_{0}^{2} \omega^{2} u / 4+11 a_{0}^{2} \omega^{2} u^{2} / 4-a_{0}^{2} \omega^{2} u^{3}+v-25 \omega^{2} v+a_{0}^{2} \omega^{2} v / 2+5 a_{0}^{2} \omega^{2} u v / 2 \\
& +\cdots=0
\end{aligned}
$$

From the first equation of Eq. (23), it can be written as:

$$
\omega^{2}=(1-u-v) /\left(1-a_{0}^{2} / 4-u-a_{0}^{2} u / 2-11 a_{0}^{2} u^{2} / 4-v+3 a_{0}^{2} v / 4+\cdots\right) .
$$

With the help of Eq. (24), $\omega^{2}$ is eliminated from the second and third equations of Eq. (23) and then simplifying, the nonlinear algebraic equations of $u$ and $v$ are obtained as: 


$$
\begin{aligned}
& u=\lambda_{0}\left(-1+5 u-14 u^{2}+32 u^{2} / a_{0}^{2}+8 u^{3}+2 u^{4}+13 v-16 u v-31 u^{2} v+\cdots\right) \\
& v=\mu_{0}\left(-7 u+18 u^{2}-15 u^{3}+4 u^{4}+v+13 u v-23 u^{2} v-3 v^{2}-39 u v^{2}-\cdots\right)
\end{aligned}
$$

where $\mu_{0}=a_{0}^{2} / 96$ and $\lambda_{0}$ is given in Eq. (12). The algebraic relation between $\lambda_{0}$ and $\mu_{0}$ is:

$$
\mu_{0}=\lambda_{0} / 3
$$

Therefore, Eq. (26) takes the form:

$$
v=\lambda_{0}\left(-7 u+18 u^{2}-15 u^{3}+4 u^{4}+v+13 u v-23 u^{2} v-3 v^{2}-39 u v^{2}-\cdots\right) / 3 .
$$

The power series solution of Eq. (25) and Eq. (28) in terms of $\lambda_{0}$ are:

$$
\begin{aligned}
& u=-\lambda_{0}-5 \lambda_{0}^{2}+\left(-26 / 3+32 / a_{0}^{2}\right) \lambda_{0}^{3}+\cdots \\
& v=7 \lambda_{0}^{2} / 2+166 \lambda_{0}^{3} / 9+\left(2194 / 27-448 / 3 a_{0}^{2}\right) \lambda_{0}^{4}+\cdots
\end{aligned}
$$

Substituting the values of $u$ and $v$ from Eqs. (29)-(30) into Eq. (24), the third-order approximate angular frequency is:

$$
\omega=\left(1+\frac{a_{0}^{2}}{8}+\frac{3 a_{0}^{4}}{256}+\frac{a_{0}^{6}}{6144}-\frac{305 a_{0}^{8}}{2359296}-\frac{161 a_{0}^{10}}{3538944}+\cdots\right) .
$$

Thus, the third-order approximate period of Eq. (8) is:

$$
T_{3}=2 \pi\left(1-\frac{a_{0}^{2}}{8}+\frac{a_{0}^{4}}{256}+\frac{5 a_{0}^{6}}{6144}+\frac{0.55 a_{0}^{8}}{262144}+\cdots\right) .
$$

The third-order approximation of Eq. (22) measures a more correct result when a suitable truncation principle is used. Using the truncation principle, Eq. (23), takes the following form:

$$
\begin{aligned}
& 1-\omega^{2}+a_{0}^{2} \omega^{2} / 4-u+\omega^{2} u+a_{0}^{2} \omega^{2} u / 2+11 a_{0}^{2} \omega^{2} u^{2} / 4-7 a_{0}^{2} \omega^{2} u^{3} / 4 \\
& -v+\omega^{2} v-3 a_{0}^{2} \omega^{2} v / 4+15 a_{0}^{2} \omega^{2} u v / 4=0, \\
& -a_{0}^{2} \omega^{2} / 4+u-9 \omega^{2} u+5 a_{0}^{2} \omega^{2} u / 4-7 a_{0}^{2} \omega^{2} u^{2} / 4+3 a_{0}^{2} \omega^{2} u^{3} / 2 \\
& +3 a_{0}^{2} \omega^{2} v-a_{0}^{2} \omega^{2} u v / 4=0 \\
& -7 a_{0}^{2} \omega^{2} u / 4+11 a_{0}^{2} \omega^{2} u^{2} / 4-a_{0}^{2} \omega^{2} u^{3} / 2+v-25 \omega^{2} v+a_{0}^{2} \omega^{2} v / 2 \\
& +5 a_{0}^{2} \omega^{2} u v / 4=0
\end{aligned}
$$

The first equation of Eq. (33), can be written as:

$$
\omega^{2}=(1-u-v) /\left(1-a_{0}^{2} / 4-u-a_{0}^{2} u / 2-11 a_{0}^{2} u^{2} / 4-v+3 a_{0}^{2} v / 4+\cdots\right) .
$$

By using the same mathematical manipulation discussed above, the nonlinear algebraic equations of $u$ and $v$ are: 


$$
\begin{aligned}
& u=\lambda_{0}\left(-1+5 u-14 u^{2}+32 u^{2} / a_{0}^{2}+2 u^{3}+u^{4}+13 v-15 u v-7 u^{2} v+\cdots\right) \\
& v=\mu_{0}\left(-7 u+18 u^{2}-13 u^{3}+2 u^{4}+v+8 u v-27 u^{2} v+v^{2}-20 u v^{2}+\cdots\right)
\end{aligned}
$$

where $\lambda_{0}$ and $\mu_{0}$ are given in Eqs. (25)-(26).

The power series solution of Eqs. (35)-(36) in terms of $\lambda_{0}$ are:

$$
\begin{aligned}
& u=-\lambda_{0}-5 \lambda_{0}^{2}+\left(-26 / 3+32 / a_{0}^{2}\right) \lambda_{0}^{3}+\left(804 / 9+1216 / 3 a_{0}^{2}\right) \lambda_{0}^{4}+\cdots, \\
& v=7 \lambda_{0}^{2} / 2+166 \lambda_{0}^{3} / 9+\left(2281 / 27-448 / 3 a_{0}^{2}\right) \lambda_{0}^{4}+\cdots
\end{aligned}
$$

Substituting the values of $u$ and $v$ from Eqs. (37)-(38) into the Eq. (34), the third-order approximate angular frequency by using truncation principle is:

$$
\begin{aligned}
& \omega=\left(1+\frac{a_{0}^{2}}{8}+\frac{3 a_{0}^{4}}{256}+\frac{a_{0}^{6}}{6144}-\frac{53 a_{0}^{8}}{2359296}-\frac{263 a_{0}^{10}}{56623104}+\cdots\right), \\
& T_{3}^{\text {truc }}=2 \pi\left(1-\frac{a_{0}^{2}}{8}+\frac{a_{0}^{4}}{256}+\frac{5 a_{0}^{6}}{6144}-\frac{27.4 a_{0}^{8}}{262144}+\cdots\right) .
\end{aligned}
$$

\section{RESULTS AND DISCUSSION}

The accuracy of the approximate periods has been illustrated by comparing with the exact period $T_{e x}$ that is stated in [6]. For this nonlinear problem, the exact period is

$$
T_{e x}=2 \pi\left(1-\frac{a_{0}^{2}}{8}+\frac{a_{0}^{4}}{256}+\frac{5 a_{0}^{6}}{6144}-\frac{7 a_{0}^{8}}{262144}-\frac{133 a_{0}^{10}}{10485760}+\cdots\right) .
$$

The second- and third-order approximate periods obtained by applying truncation and without truncation principle to the nonlinear oscillator are defined in Eq. (8).

$$
\begin{aligned}
& T_{2}=2 \pi\left(1-\frac{a_{0}^{2}}{8}+\frac{a_{0}^{4}}{256}+\frac{a_{0}^{6}}{4096}-\frac{7 a_{0}^{8}}{65536}+\cdots\right), \\
& T_{3}=2 \pi\left(1-\frac{a_{0}^{2}}{8}+\frac{a_{0}^{4}}{256}+\frac{5 a_{0}^{6}}{6144}+\frac{0.55 a_{0}^{8}}{262144}+\cdots\right) .
\end{aligned}
$$

In the case of truncation principle:

$$
\begin{aligned}
& T_{2}^{\text {truc }}=2 \pi\left(1-\frac{a_{0}^{2}}{8}+\frac{a_{0}^{4}}{256}+\frac{5.6 a_{0}^{6}}{6144}+\frac{15 a_{0}^{8}}{131072}+\cdots\right), \\
& T_{3}^{\text {truc }}=2 \pi\left(1-\frac{a_{0}^{2}}{8}+\frac{a_{0}^{4}}{256}+\frac{5 a_{0}^{6}}{6144}-\frac{27.4 a_{0}^{8}}{262144}+\cdots\right) .
\end{aligned}
$$


Comparing all the approximate periods, the accuracy of the proposed analytical technique using the truncation principle is better than without the truncation principle. It is highly remarkable that, using the truncation principle, the third-order approximate period gives almost the same result as the exact period. High accuracy period and very simple solution procedure reveal the novelty and reliability of the proposed harmonic balance method. The advantages of the proposed technique include its simplicity and computational efficiency, and the ability to objectively find better agreement in third-order approximate period by applying the truncation principle.

\section{CONCLUSION}

In this paper, an analytical technique has been proposed based on the harmonic balance method to determine approximate periods to the nonlinear oscillator with the square of the angular frequency depending quadratically on the velocity. The solution procedure of the proposed technique is very simple and straightforward. In the presented problem, the approximate periods obtained using the proposed technique shows much better agreement with the corresponding exact period. It is noted that, the third-order approximate period obtained using the truncation principle is almost identical compared with the numerically obtained exact period. High accuracy of the approximate periods obtained from the problem reveals the versatility of the proposed technique in solving strongly nonlinear classes of problems. It can be concluded that the proposed technique is a better and efficient alternative to the existing Lindstedt-Poinare' perturbation-based method and classical harmonic balance method for approximating solutions for strongly nonlinear classes of problems.

\section{ACKNOWLEDGEMENT}

The authors would like to thank the Ministry of Higher Education (MOHE), Malaysia for financial support under the Project FRGS 14-156-0397. The authors also express their gratitude to the reviewers for their useful suggestions and comments which significantly improved the original manuscript.

\section{REFERENCES}

[1] Leissa AW. (1993) Vibration of Plates, Washington DC: Acoustical Society of America.

[2] Chopra AK. (1995) Dynamic of Structures, Theory and Application to Earthquake Engineering, New Jersey: Prentice-Hall, USA.

[3] Nayfeh AH. (1973)Perturbation Methods, Jhon Wiley, New York, USA.

[4] Elmas N, Boyaci H. (2014) A new perturbation technique in solution of nonlinear differential equations by using variable transformation. Applied Mathematics and Computation, 227:422-427.

[5] AzadAK, Hosen MA, RahmanMS. (2012) A perturbation technique to compute initial amplitude and phase for the Krylov-Bogoliubov-Mitropolskii method. Tamkang Journal of Mathematics, 43(4):563-575.

[6] BelendezA, BelendezT, HernandezA, GallegoS, OrtunoM,NeippC. (2007) Comments on "investigation of the properties of the period for the nonlinear oscillator $\ddot{x}+\left(1+\dot{x}^{2}\right) x=0$ ". Journal of Sound and Vibration, 303(3-5):925-930.

[7] Belendez A, Hernandez A, Belendez T, Neipp C, Marquez M. (2007) Asymptotic representation of the period for the nonlinear oscillator. Journal of Sound and Vibration, 299(1-2):403-408.

[8] Marincaa V, Herisanu N. (2010) Determination of periodic solutions for the motion of a particle on a rotating parabola by means of the optimal homotopy asymptotic method. Journal of Sound Vibration, 329(9):1450-1459. 
[9] Belendez A. (2009) Homotopy perturbation method for a conservative $x^{1 / 3}$ force nonlinear oscillator. Computers \& Mathematics with Applications, 58(11-12):2267-2273.

[10] Leung AYT, Guo ZJ. (2009) Homotopy perturbation for conservative Helmholt-Duffing oscillator. Journal of Sound and Vibration, 325(1-2):287-296.

[11] He JH. (2004) The homotopy perturbation method for nonlinear oscillators with discontinuities. Applied Mathematics and Computation, 151(1):287-292.

[12] Suleman M, Wu Q. (2015) Comparative solution of nonlinear quintic cubic oscillator using modified homotopy perturbation method. Advances in Mathematical Physics, Article ID 932905:5.

[13] Belendez A, Pascual C, Belendez T, Hernandez A. (2009) Solution for an anti-symmetric quadratic nonlinear oscillator by a modified He's homotopy perturbation method. Nonlinear Analysis, 10(1):416-427.

[14] Belendez A, Pascual C, OrtunoM, Belendez T, Gallego S. (2009) Application of a modified He's homotopy perturbation method to obtain higher-order approximations to a nonlinear oscillator with discontinuities. Nonlinear analysis, 10(2):601-610.

[15] Ganji SS, Ganji DD, Karimpour S, Babazadeh H. (2009) Applications of a modified he's homotopy perturbation method to obtain second-order approximations of the coupled twodegree-of-freedom systems. International Journal of Nonlinear Sciences and Numerical Simulation, 10(3):303-312.

[16] Ozis T, YildirimA. (2007) Determination of periodic solution for a $u^{1 / 3}$ force by He's modified Lindstedt-Poincare method. Journal of Sound Vibration, 301(1-2):415-419.

[17] Razzak MA, AlamMZ, Sharif MN. (2018) Modified multiple time scale method for solving strongly nonlinear damped forced vibration systems. Results in Physics, 8:231-238.

[18] Azami R, Ganji DD, Babazadeh H, Dvavodi AG, Ganji SS. (2009) He's Max-Min method for the relativistic oscillator and high order Duffing equation. International Journal of Modern Physics B, 23(32):5915-5927.

[19] Alex EZ, Rodríguez CA, Romero OM. (2012) Application of the elliptic balance method to a nonlinear singular oscillator. Applied Mathematics and Computation, 218(22):1111211117.

[20] Akbari M, Ganji DD, Ahmadi A, Kachapi SHH. (2014) Analyzing the nonlinear vibrational wave differential equation for the simplified model of tower cranes by algebraic method. Frontiers of Mechanical Engineering, 9(1):58-70.

[21] Huseyin T, Murat S. (2018) A local differential transform approach for the cubic nonlinear Duffing oscillator with damping term. Scientia Iranica, Available Online from 20 January.

[22] Younesian D, Askari H, Saadatnia Z, Yazdi MK. (2010) Frequency analysis of strongly nonlinear generalized Duffing oscillators using He's frequency-amplitude formulation and He's energy balance method. Computers \& Mathematics with Applications, 59(9):32223228.

[23] Razzak MA. (2017) A simple new iterative method for solving strongly nonlinear oscillator systems having a rational and an irrational force. Alexandria Engineering Journal, In press.

[24] Yildirim A, Askari H, Yazdi MK, Khan Y. (2012) A relationship between three analytical approaches to nonlinear problems. Applied Mathematics Letter, 25(11):1729-1733.

[25] Razzak MA,RahmanMM. (2015) Application of new novel energy balance method to strongly nonlinear oscillator system. Results in Physics, 5:304-308.

[26] Molla MHU, Alam MS. (2017) Higher accuracy analytical approximations to nonlinear oscillators with discontinuity by energy balance method. Results in Physics, 7:2104-2110.

[27] Askari H, Saadatnia Z, Esmailzadeh E, Younesian D. (2014) Multi-frequency excitation of stiffened triangular plates for large amplitude oscillations. Journal of Sound and Vibration, 333(22):5817-5835.

[28] Younesian D, Askari H, Saadatnia Z, Yazdi MK. (2012) Analytical approximate solutions for the generalized nonlinear oscillator. Applicable Analysis, 91(5):965-977.

[29] Hosen MA, Chowdhury MSH, Ali MY, Ismail AF. (2017) An analytical approximation technique for the duffing oscillator based on the energy balance method. Italian Journal of Pure and Applied Mathematics, 37:455-466. 
[30] Yamgoue SB, Bogning JR, Jiotsa AK, Kofane TC. (2010) Rational harmonic balance-based approximate solutions to nonlinear single-degree-of-freedom oscillator equations. PhysicaScripta, 81:035003.

[31] Beatty J, Mickens RE. (2005) A qualitative study of the solution to the differential equation $\ddot{x}+\left(1+\dot{x}^{2}\right) x=0$. Journal of Sound and Vibration, 283:475-477.

[32] Mickens RE. (2006) Investigation of the properties of the period for the nonlinear oscillator $\ddot{x}+\left(1+\dot{x}^{2}\right) x=0$. Journal of Sound and Vibration, 292(3-5):1031-1035.

[33] Mickens RE. (1986) A generalization of the method of harmonic balance. Journal of Sound and Vibration, 111:515-518.

[34] Hosen MA, Chowdhury MSH. (2015) A new analytical technique based on harmonic balance method to determine approximate periods for Duffing-harmonic oscillator. Alexandria Engineering Journal, 54(2):233-239.

[35] Hosen MA. (2014) Approximate solutions of the equation of motion's of the rigid rod which rocks on the circular surface without slipping. Ain Shams Engineering Journal, 5(3):895899.

[36] Hu H. (2006) Solution of a quadratic nonlinear oscillator by the method of harmonic balance. Journal of Sound and Vibration, 293(1-2):462-468.

[37] Chowdhury MSH, Hosen MA, Ahmad K, Ali MY, Ismail AF. (2017) High-order approximate solutions of strongly nonlinear cubic-quintic Duffing oscillator based on the harmonic balance method. Results in Physics, 7:3962-3967.

[38] Hosen MA, Chowdhury MSH. (2015) A new reliable analytical solution for strongly nonlinear oscillator with cubic and harmonic restoring force. Results in Physics, 5:111-114. 